\title{
Evaluation of Anatomical Variations in Nose and Paranasal Sinuses by using Multidetector Computed Tomography
}

\author{
Mallikarjun M. Devareddy ${ }^{1}$, Shilpa Devakar ${ }^{2}$ \\ ${ }^{1}$ Associate Professor, Department of Radio Diagnosis, Navodaya Medical College Raichur, ${ }^{2}$ Associate Professor, Department \\ of Radio Diagnosis, Raichur Institute of Medical Science (RIMS), Raichur, India
}

Corresponding author: Dr. Shilpa Devakar, No. 40 Doctor's Quarters, RIMS Campus Raichur, India

DOI: http://dx.doi.org/10.21276/ijcmsr.2019.4.3.32

How to cite this article: Mallikarjun M. Devareddy, Shilpa Devakar. Evaluation of anatomical variations in nose and paranasal sinuses by using multidetector computed tomography. International Journal of Contemporary Medicine Surgery and Radiology. 2019;4(3):C146-C151.

\section{A B S T R A C T}

Introduction: The variants can impair free airflow of paranasal sinuses by causing narrowing or total obstruction and can lead to repeated sinusitis. The anatomical variants can lead to intracranial and intraorbital complications during procedures like Functional Endoscopic Sinus Surgery (FESS). Hence the knowledge about the normal anatomy and its variants of paranasal sinuses helps in early diagnosis as well as in avoiding surgical complications.

Material and methods: The study was performed at Navodaya medical college hospital and research centre, Raichur.100 patients from Jan-2017 to Jun-2018 were studied. All the 100 patients in the sample were referred from the ENT OPD and wards for CT PNS. Patients were subjected to CT scans of PNS using GE Brivo CT385 16 slice MDCT images were reviewed in both bone and soft tissue algorithms.

Results: Deviated nasal septum was the most common variation in 62(62\%) followed by concha bullosa in 32(32\%).Other variations found were Ethmoidal bulla in 30(30\%) patients, Paradoxical middle turbinate in 9(9\%), Frontal sinus septations in 26(26\%). Concha bullosa in 20(20\%), prominent Agger Nasi cells in 26(26\%), Haller cells in 16(16\%), Onodi cells in $6(6 \%)$, Supra-orbital cells in 4(4\%) Maxillary sinus septa in 15(15\%) and pneumatization of crista galli in 9(9\%) patients. Conclusion: Computed Tomography of the paranasal sinuses has improved the visualization of paranasal sinus anatomy and has allowed greater accuracy in evaluating paranasal sinus disease. The presence of anatomical variants does not establish genesis of disease but these variations can predispose patients to intro-op complications. The radiologist must pay close attention to variants and provide road map to surgeons and help to avoid possible complications.

Keywords: Computed Tomography; Paranasal Sinuses, Nasal Septum, Concha Bullosa

\section{INTRODUCTION}

Paranasal sinuses (PNS) are the air containing spaces in skull. They lighten the skull, humidify air and provide resonance to voice. The paranasal sinuses are maxillary, ethmoid, frontal and sphenoid sinuses.

The precise knowledge of the anatomy of paranasal sinuses is essential for clinician. ${ }^{1}$ With the advent of functional endoscopic sinus surgery (FESS) and computed tomography (CT) imaging, considerable attention has been given to paranasal region anatomy. Various imaging modalities are available for evaluation of paranasal sinuses. Conventional radiography provides useful information in the diseases of maxillary and frontal sinuses but has limited role in evaluation of nasal cavity, ethmoid and sphenoid sinuses. Conventional radiography does not delineate osteomeatal complexes. Multi detector computed tomography provides the details of bone, soft tissue and air in the paranasal sinuses and accurate depiction of the anatomy, the anatomical variants and the extent of the pathology in and around the paranasal sinuses. Accurate delineation of the anatomic locales and disease in the paranasal sinuses are provided by axial sections, direct coronal scanning and sagittal reconstructions. The investigation of choice for the evaluation of the osteomeatal complexes and the recesses of the PNS is Computed tomography. It provides a preoperative road map for functional endoscopic sinus surgery. A combination of CT and diagnostic endoscopy is the keystone in the management of paranasal sinus diseases. CT imaging is now well established as an alternative to radiographs. $^{2}$

MRI is used as an important modality in the evaluation of the soft tissue pathologies and tumors of the PNS due to its multiplanar capability and excellent soft tissue resolution. The major limitation of Magnetic resonance imaging is its inability to display the skeletal anatomy as compared to CT. So, Computed tomography is currently used as a method of choice in the evaluation of the paranasal sinuses and adjacent structures. $^{2}$

The inflammatory disease of paranasal sinuses is a frequently encountered health problem. Traditionally, the modality of choice in evaluation of sinus pathology was plain radiograph. Clinical and radiographic emphasis was given primarily to 
the frontal and maxillary sinuses. In recent past, it is evident that sinusitis is primarily a clinical diagnosis. Imaging is performed to document the extent of disease and to provide an accurate exhibit of the anatomy of the sinonasal system. Imaging provides road map for guiding the fess procedure. Presently, computed tomography (CT) is the modality of choice for the imaging evaluation of the morphology. Most of the patients with sinonasal inflammatory disease are initially treated medically but often the disease does not resolve. Patients with persistent disease require surgical intervention. The surgical treatment for refractory inflammatory sinus disease has undergone significant changes in the last two decades. The advances are due to improved understanding of the mucociliary clearance pathways in the nasal cavity and PNS, improved endoscopes that direct access to nasal cavity and ethmoid sinus drainage portals and high resolution CT images that provide an accurate display of the anatomy and its variations. Study aimed to assess the anatomical variations of paranasal sinuses and their association with paranasal sinus Pathology.

\section{MATERIAL AND METHODS}

The present hospital based prospective observational study was performed at Navodaya medical college hospital and research centre, Raichur. 100 patients from Jan-2017 to Jun- 2018 were studied. All the 100 patients in the sample were referred from the ENT OPD and wards for CT PNS. Patients were subjected to CT scans of PNS using GE Brivo CT385 16 - slice. Images were reviewed in both bone and soft tissue algorithms for the variations. The patients were explained about the study in their language.

\section{Inclusion criteria}

Patients included in the study were those with complaints pertaining to PNS, and referred from the ENT OPD and wards.

\section{Exclusion criteria}

1. Facial trauma.

2. Previous sinonasal surgery (excluding nasoantral window antrostomy).

3. Sinonasal anatomy alteration or obscuration due to inflammatory diseases (when bony detail was obscured by polypoid mucosal disease)

4. Paranasal sinus neoplasm.

\section{Technique}

Both axial and coronal CT scan of patients was taken and the details of the anatomical variations were recorded (figure 1-4).

\section{Patient position}

Supine for axial sections

Supine/ prone with neck extended for coronal section

\section{Angulation}

Parallel to hard palate for axial sections Perpendicular to hard palate for coronal section

\section{Thickness}

$5 \mathrm{~mm}$ for both coronal and axial sections. $3 \mathrm{~mm}$ were taken at osteomeatal unit on coronal section.

\section{Extent}

Coronal - posterior margin of sphenoid sinus to anterior margin of frontal sinus. Axial - hard palate to upper margin of frontal sinus. Exposure: $120 \mathrm{kvp}, 130$ mas, 1.5 seconds scan time.

\section{Bone window}

Window width $=4000 \mathrm{HU}$ Window level $=500 \mathrm{HU}$

Soft tissue window: Window width $=90 \mathrm{HU}$ Window level $=40 \mathrm{HU}$

\section{STATISTICAL ANALYSIS}

Descriptive statistics such as mean, SD and percentage was used to present the data. Association with variations was calculated by using chi-square test. A p-value less than 0.05 were considered as significant. SPSS for windows (version 20.0) was employed for statistical analysis.

\section{RESULTS}

Among 100 patients selected for the study of variations in the paranasal sinus 49 (49\%) were males and 51 (51\%) females. Majority of the subjects, patients were in the age

\begin{tabular}{|l|c|c|c|}
\hline & Frequency & Percent & P value \\
\hline Normal & 3 & $38.0 \%$ & \multirow{2}{*}{0.001} \\
\hline Left & 28 & $28.0 \%$ & \multirow{2}{*}{$0.0 \%$} \\
\hline Right & 26 & $26.0 \%$ & \\
\hline 'S' Shape & 08 & $8.0 \%$ & \\
\cline { 1 - 3 } Total & 100 & $100.0 \%$ & \\
\cline { 1 - 2 } Table-1: Frequency of Occurrence of Deviated Nasal Septum \\
\hline
\end{tabular}

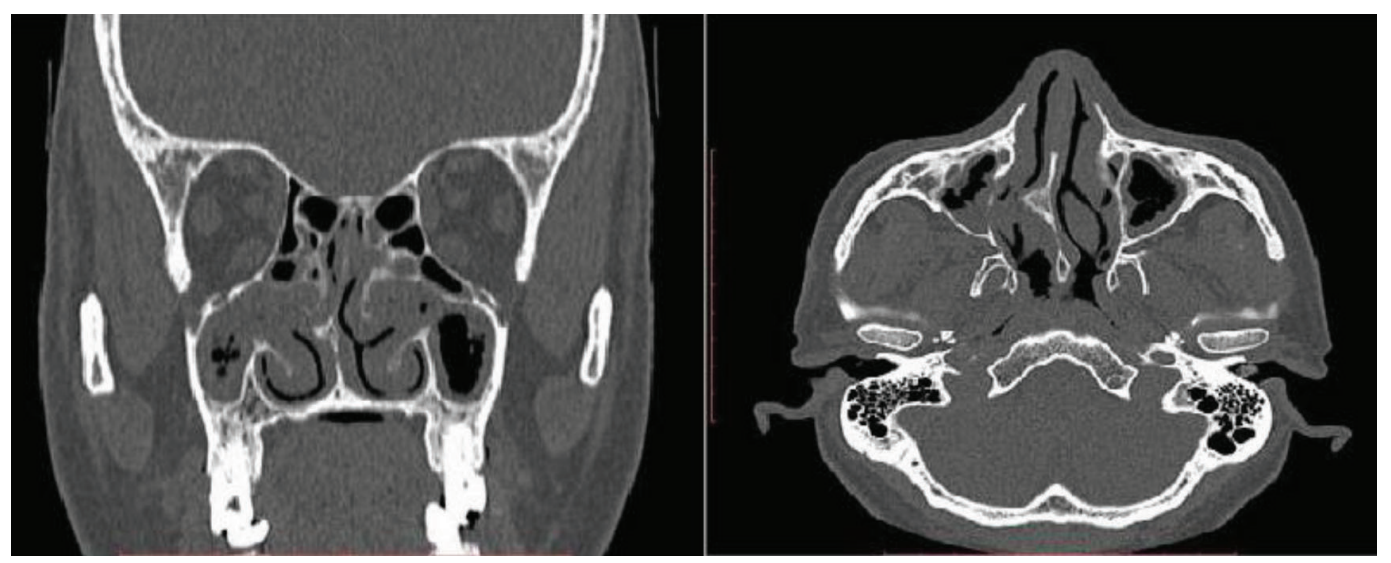

Figure-1: Coronal \& axial section showing right sided deviated nasal septum with bony spur 


\begin{tabular}{|l|c|c|}
\hline Types & No. of patients & Percentage \\
\hline I & 37 & $37 \%$ \\
\hline II & 13 & $13 \%$ \\
\hline III & 11 & $8 \%$ \\
\hline IV & 8 & $16 \%$ \\
\hline V & 16 & $9 \%$ \\
\hline VI & 9 & $6 \%$ \\
\hline VII & 6 & $100 \%$ \\
\hline Total & 100 & \\
\hline \multicolumn{2}{|c|}{ Table-2: Types of Deviated Nasal Septum } \\
\hline
\end{tabular}

\begin{tabular}{|l|c|c|c|}
\hline Special cells & Frequency & Percentage & p-value \\
\hline Haller cell & 16 & 16 & $<0.0001$ \\
\hline Onodi cell & 6 & 6 & $<0.0001$ \\
\hline Agar Nasi cell & 26 & 26 & $<0.0001$ \\
\hline Supraorbital cell & 4 & 4 & $<0.0001$ \\
\hline \multicolumn{2}{|c|}{ Table - 3: Occurrence of Different Special Cells } \\
\hline
\end{tabular}

\begin{tabular}{|l|c|c|c|c|}
\hline Mucosal abnormalities in individual sinuses & \multicolumn{2}{c|}{ Total } \\
\hline Sinuses & Bilateral & Unilateral & Frequency & $\%$ \\
\hline Maxillary & Frequency & Frequency & 52 & 36.1 \\
\hline Frontal & 36 & 16 & 24 & 16.6 \\
\hline Anterior ethmoid & 14 & 10 & 34 & 23.6 \\
\hline Posterior ethmoid & 10 & 24 & 22 & 15.2 \\
\hline Sphenoid & 10 & 12 & 12 & 8.3 \\
\hline \multicolumn{2}{|c|}{ Table-4: Mucosal abnormalities in individual sinuses } & \\
\hline
\end{tabular}

\begin{tabular}{|l|l|c|c|c|}
\hline & & \multicolumn{3}{|c|}{ Mucosal abnormalities in sinus } \\
\hline & & Present & Absent & Total \\
\hline \multirow{3}{*}{ Anatomical variations in PNS } & Present & 72 & 13 & 95 \\
\cline { 2 - 5 } & Absent & 2 & 3 & 5 \\
\cline { 2 - 5 } & Total & 74 & 16 & 100 \\
\hline
\end{tabular}

\begin{tabular}{|l|c|c|}
\hline Anatomical variations & $\begin{array}{c}\text { No of } \\
\text { cases }\end{array}$ & $\begin{array}{c}\text { Percentage } \\
\text { (\%) }\end{array}$ \\
\hline Deviated nasal septum & 62 & 22.0 \\
\hline Concha bullosa & 32 & 11.3 \\
\hline Bulla ethmoidalis & 30 & 10.6 \\
\hline Agger nasi cell & 26 & 9.2 \\
\hline Frontal sinus septation & 26 & 9.2 \\
\hline Haller cell & 16 & 5.6 \\
\hline Maxillary sinus septation & 15 & 5.3 \\
\hline Frontal sinus hypoplasia & 15 & 5.3 \\
\hline Sphenoid sinus septation & 13 & 4.6 \\
\hline Paradoxical middle turbinate & 9 & 3.2 \\
\hline Crista galli pneumatization & 9 & 3.2 \\
\hline Frontal sinus agenesis & 7 & 2.4 \\
\hline Onodi cells & 6 & 2.1 \\
\hline Superior turbinate pneumatization & 5 & 1.7 \\
\hline Supraorbital cells & 4 & 1.4 \\
\hline Maxillary sinus hypoplasia & 3 & 1.0 \\
\hline Sphenoid sinus hypoplasia & 2 & 0.7 \\
\hline Inferior turbinate pneumatisation & 1 & 0.3 \\
\hline Total & 281 & 100 \\
\hline Table-6: Overall distribution of anatomical variants in PNS \\
\hline
\end{tabular}

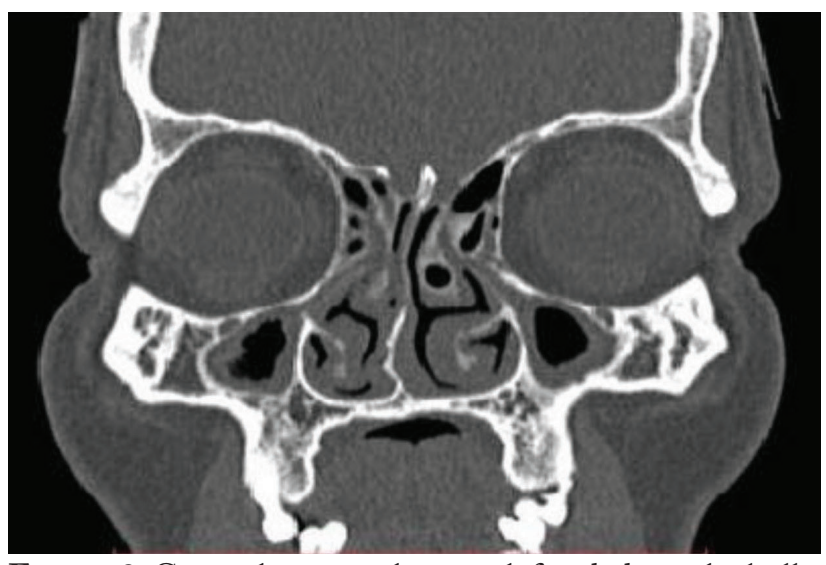

Figure-2: Coronal section showing left sided concha bullosa with right sided DNS

group of 20-40 yrs. This was found to be statistically as highly significant at .000 level. Gender-wise, no statistical difference was observed. Chi-square test value of 5.1 was found to be non- significant $(\mathrm{P}=0.4)$ (table-1).

In our study $62 \%$ of patients showed deviated nasal septum and also showed slight predominance to the left side (28\%) as compared to right side (26\%). On statistical basis p values 


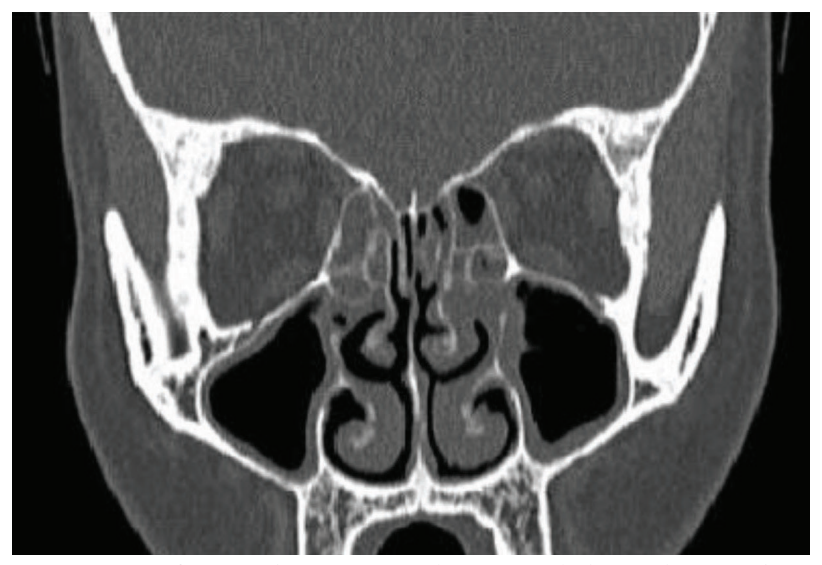

Figure-3: Coronal section showing bilateral paradoxical middle turbinate

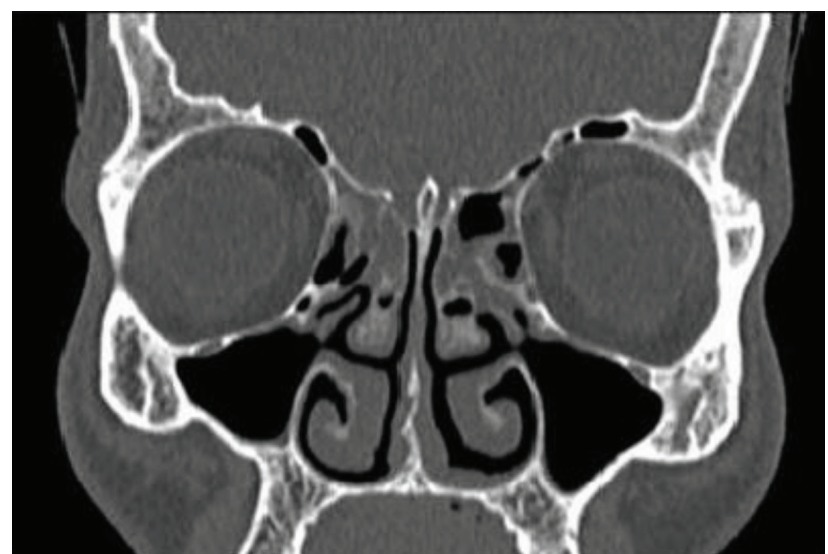

Figure-4: Coronal section showing left sided Agger nasi cell

were also significant $(\mathrm{p}=0.000)$ (table-2).

As far as the special cells are considered in the paranasal sinuses the variation of occurrence of these special cells were found to be significant as their $\mathrm{p}$ values are below 0.05 (table-3).

\section{DISCUSSION}

The nasal fossae and para nasal sinuses together constitute single anatomical and functional unit. Covered by the same mucosa, the paranasal sinuses communicate with the nasal cavities via small openings and narrow ducts that allow both aeration and sinus drainage. This region is subject to a large variety of lesions. Congenital anomalies and normal anatomical variations in this region are important as they may have pathological consequence or may be the source of difficulty/ complication during surgery. Because of structural superimposition, conventional radiology does not give precise exploration of the region, especially of the anterior ethmoidal air cells, the frontal recess, and the upper two thirds of the nasal cavities, zones closely related to sinus physiopathology, and therefore interesting from the point of view of applied anatomy. The revolutionary changes in the surgical treatment of sinusitis in recent years, particularly in endonasal endoscopic surgery, require the clinician to have a precise knowledge of nasal sinus anatomy and of the large number of anatomical variants in the region, many of which are detectable only by the use of CT.

Advent of relatively less invasive techniques of functional endoscopic sinus surgery has provided an important role for MDCT of paranasal sinus both as a diagnostic tool and as an important part of preoperative planning. The variations compromise already narrowed drainage pathway and produce significant obstruction.

\section{Age and sex determination}

Among 100 patients selected for the study of variations in the paranasal sinus $49(49 \%)$ were males and $51(51 \%)$ females. Majority of the subjects, patients were in the age group of 20-40 yrs. We found in our study that most of the patients in the age groups of $<20,21-30$, and 31-40 years and very few of them in higher age groups. This was found to be statistically as highly significant at .000 level. Gender-wise, no statistical difference was observed. Chi-square test value of 5.1 was found to be non- significant $(\mathrm{P}=.0 .4)$.

\section{Deviated nasal septum}

In a study of 110 subjects by Perez-Pinas J Sabate et al, 80 subjects showed DNS. Most were non traumatic deviations of the septum (64 cases, 72\%); the numbers of left and rightward deviations were similar, with a slight predominance of the former. ${ }^{3}$

According to John Earwaker, deviated nasal septum (55\%) is the most common variation, in his study there is slight predominance towards right side. ${ }^{4}$

Talaiepour AR et al study showed Nasal septal deviation was found in $63 \%$ of which $28.0 \%$ deviated to the right and $31.5 \%$ to the left. Bilateral deviation was observed in 3.5\% of all cases. ${ }^{5}$

Gupta S et al study showed Nasal septal deviation was found in $78.80 \%$ followed by paradoxical middle turbinate $(46.10 \%){ }^{6}$

In our study $62 \%$ of patients showed deviated nasal septum and also showed slight predominance to the left side (28\%) as compared to right side (26\%). On statistical basis $\mathrm{p}$ values were also significant $(\mathrm{p}=0.000)$.

\section{Occurrence of special cells}

In the literature, the presence of Agger nasi cells varies from $10 \%$ to $98.5 \%$ as follows.

Talaiepour AR et al, study showed Agger nasi cell in 56.7\% of cases, with $17.5 \%$ on the right, $7.7 \%$ left and $31.5 \%$ of patients having Agger nasi cell as a bilateral finding. ${ }^{5}$ In another study done by Yadav R R et al reported that, Agger nasi cell is the commonest anatomical variation $(75.8 \%){ }^{7}$

In our study the occurrence of Agger nasi cells falls within the range of various studies i.e. (26\%).

Study of Talaiepour AR et al, showed Haller cells in 3.5\% of all subjects with $1.4 \%$ on the left and $2.1 \%$ bilateral; none were observed on the right side. The occurrence of Haller cell is variable according to various studies. ${ }^{5}$

Dua K, Chopra H et al, study showed occurrence of Haller cell is $16 \% .^{8}$ Jack M Gwaltney et al, study showed the occurrence of Haller cells is 45\%. ${ }^{9}$ According to Mohannad A Al Qudah, Haller cell was noted in $20 \%{ }^{10}$ In our study occurrence of Haller cells is $16 \%$. According to Talaiepour AR et al, Onodi cell appeared on $7 \%$ of the scans with $2.8 \%$ on the right, $0.7 \%$ left and $3.5 \%$ located bilaterally. ${ }^{5}$ According To John Earwaker, occurrence of Onodi cell is 191 out of 800 patients studied i.e. $24 \%{ }^{4}$ 
In study by Dua K, Chopra $\mathrm{H}$ et al, occurrence of Onodi cell is $6 \%$ out of 50 patients studied. ${ }^{8}$ In our study the occurrence of Onodi cells is $6 \%$.

Accurate delineation of optic nerve is important in preoperative planning and the presence or absence of Onodi cells can be important in preoperative planning, and can be an important factor in limiting posterior extent of endoscopic clearance. ${ }^{8}$ In our study the $\mathrm{p}$ values of various special cells was found to be statistically highly significant as they fall below $\mathrm{p}<0.05$.

\section{Cribriform plate}

In a study conducted by Soraia Ale Souza et al, it was found in their study that Keros type II was most frequently found in $73.3 \%$ of cases followed by type I in $26.3 \%$ and type III in $0.5 \%$ of cases. ${ }^{11}$

In our study the occurrence of different types of cribriform plates are as follows.

Type I is $40 \%$ Type II is $51 \%$ Type III is $09 \%$. The type of cribriform plate is important in predicting the intra operative complications during functional endoscopic sinus surgery.

\section{Frequency of variations of middle turbinate}

Literature reports a wide variation in the incidence of middle turbinate pneumatization and is as follows: Joe JK et al were reported $15 \%{ }^{12}$; Liu X et al was reported $34.85 \%{ }^{13}$, Basic N et al was reported $42 \%^{14}$, Lothrop was reported $9 \%{ }^{15}$, Davis was reported $8 \%{ }^{16}$, Shaeffer was reported $11 \% .{ }^{17}$

According to Talaiepour AR, Concha bullosa was found in $35 \%$ of the samples. Ofm these, $11.9 \%$ were on the right, $11.2 \%$ left and $11.9 \%$ occurred as a bilateral anatomic variation. $^{5}$

According to John Earwaker 443 patients showed concha bullosa out of 800 patients studied. ${ }^{4}$

In the present study, $32 \%$ of the cases showed concha bullosa out of which bilateral is the maximum of about $13 \%$ followed by right side of about $10 \%$ and least is on the left side of about $7 \%$.

Presence of a concha bullosa does not suggest a pathological finding. However, in the setting of chronic sinus disease, resection of the concha bullosa should be considered to improve paranasal sinus access. Further, the concha bullosa interior may be affected by disease in other sinuses. ${ }^{17}$

\section{Paradoxically bent middle turbinate}

A middle turbinate which is distorted such that the convex surface faces towards the meatus is in itself not pathologic but it can lead to severe narrowing of the middle meatus if mucosal derangements are present.

We found paradoxical curvature of middle turbinate in $9 \%$. Prevalence of paradoxical middle turbinate was within the range of previous studies.

\section{Occurrence of septation in various sinuses}

According to john earwaker, maxillary sinus showed septations in about 19 cases out of 800 patients studied. ${ }^{4}$

According to Abdullah BJ et al, out of 70 patients studied $68.9 \%$ showed septations in the sphenoid sinus. ${ }^{18}$

In the present study frontal sinus showed septations in about 26\%. Maxillary sinus showed septations in about 15\%. Sphenoid sinus showed septations in about $13 \%$.

\section{Hypoplasticity of various paranasal sinuses}

In a study conducted by Binali Çakur et al showed that $0.56 \%$ of cases showed hypoplastic sphenoid sinus. The diagnosis of sphenoid sinus hypoplasia is potentially important in patients in whom trans-sphenoidal hypophysectomy is indicated. ${ }^{19}$

In the present study a total of $3 \%$ of cases comprised to have hypoplastic sphenoid sinus. Maxillary sinus hypoplasia is an uncommon condition that may be misdiagnosed as chronic sinusitis. Bolger et al found the prevalence of unilateral hypoplastic maxillary sinus to be $10.4 \%$ on coronal CT scans. In our study Maxillary sinus hypoplasia showed 3\% bilaterally. ${ }^{20}$

Maxillary sinus hypoplasia predisposes to orbital penetration during endoscopic sinus surgery; therefore this bony abnormality must be recognized as well as associated anatomic variations, especially prior to sinus surgery. ${ }^{20}$

In our study Frontal sinus hypoplasia was noted in 15\% in which $3 \%$ were bilateral.

\section{Mucosal abnormalities and their association with anatomical variants}

In our study 73(\%) patients had PNS mucosal abnormalities and $23(23 \%)$ patients had no mucosal abnormalities. PNS mucosal abnormalities were seen in $72(75.7 \%)$ out of 95 patients with anatomical variants and $2(40 \%)$ out of 4 patients without anatomical Variants (table-5,6).

From this observation our study also reveals that the presence of anatomical variants may predispose but not always with the occurrence of sinus pathology. However, it is important for surgeon to be aware of variations that may predispose patients to increased risk of intra-operative complications. The radiologist must pay close attention to anatomical variants in the preoperative evaluation and help avoid possible complications and improve success of management strategies.

\section{CONCLUSION}

MDCT is the imaging modality of choice for the evaluation of the anatomical variations in paranasal sinuses.

Thin sections provide more detailed variations on MDCT scan. Computed Tomography of the paranasal sinuses has improved the visualization of paranasal sinus anatomy and has allowed greater accuracy in evaluating paranasal sinus disease.

In our study DNS is the most common anatomical variation. Among the special cells, Agger nasi cell is the most common type. Septations in paranasal sinuses is most common in frontal sinus. Type I variety is the commonest type of uncinate insertion.

Type II variety of the cribriform plate is the most common type.

Prevalence of multiple anatomical variations was more common in our study in comparison to single anatomical variation

The presence of anatomical variants does not establish genesis of disease but these variations can predispose patients to intro-op complications. The radiologist, thus, must pay close attention to variants and provide road map to surgeons and help avoid possible complications. 


\section{REFERENCE}

1. MohammedAtikAhmed,sureshKanmadi.Role of Computed tomography in Evaluation of Congenital Anatomical Variations in ParanasalSinuses.Int J Biol Med Res.2015;6(1):4775-4781

2. White PS, Cowan IA, Robertson MS. Limited CT scanning techniques of the paranasal sinuses. The Journal of Laryngology \& Otology. 1991;105(1):20-3.

3. Perez-Pinas I, Sabate J, Carmona A, Catalina-Herrera $\mathrm{CJ}$, Jimenez-Castellanos J. Anatomical variations in the human paranasal sinus region studied by CT. The Journal of Anatomy. 2000;197(2):221-7.

4. Earwaker J. Anatomic variants in sinonasal CT. Radiographics. 1993;13(2):381-415.

5. Talaiepour AR, Sazgar AA, Bagheri A. Anatomic variations of the paranasal sinuses on $\mathrm{CT}$ scan images. Journal of Dentistry of Tehran University of Medical Sciences. 2005:142-6.

6. Gupta S, Gurjar N,Mishra HK. Computed tomographic evaluation of anatomical valuations of paranasal sinus region. Int J Res Med Sci 2016;4:2909-13.

7. Yadav RR, Ansari MA, Humagain M, Mishra D. Assessment of anatomical variations of nose and paranasal sinuses in mutidetetor computed tomography. J. of Institute of Medicine, 2017;39(1):49-54.

8. Dua K, Chopra H, Munjal M. CT Scan variations in chronic sinusitis. IJRI 2005;15(3):315-20.

9. Gwaltney Jr JM, Phillips CD, Miller RD, Riker DK. Computed tomographic study of the common cold. New England Journal of Medicine. 1994;330(1):25-30.

10. Mohannad A Al-Qudah. Anatomical Variations in Sino-Nasal Region: A Computer Tomography (CT) Study. J Med J 2010;44(3):290-7.

11. Souza SA, Souza MM, Idagawa M, Wolosker ÂM, Ajzen SA. Computed tomography assessment of the ethmoid roof: a relevant region at risk in endoscopic sinus surgery. Radiologia Brasileira. 2008;41(3):143-7.

12. Joe JK, Ho SY, Yanagisawa E. Documentation of variations in sinonasal anatomy by intra-operative nasal endoscopy. Laryngoscope 2000;110(2-1):229-35.

13. Liu $\mathrm{X}$, Zhang $\mathrm{G}, \mathrm{Xu}$ G. Anatomic variations of the ostiomeatal complex and their correlation with chronic sinusitis: CT evaluation. Zhonghua Er Bi Yan Hou Ke Za Zhi 1999;34(3):143-6.

14. Basic N, Basic V, Jukic T, Basic M, Jelic M, Hat J. Computed tomographic imaging to determine the frequency of anatomical variations in pneumatization of the ethmoid bone. Eur Arch Otorhinolaryngol 1999;256(2):69-71.

15. Lothrop HA. The anatomy of the inferior ethmoidal turbinate bone with particular reference to cell formation. Surgical importance of such ethmoid cell. Ann Surgery 1903;38:233-55.

16. Davis WE. Anatomy of the paranasal sinuses. OCNA 1996;29:57-73.

17. Shaeffer SD. An anatomic approach to endoscopic intranasal ethmoidectomy. Laryngoscope 1998;108(111):1628-34

18. Abdullah BJ, Arasaratnam S, Kumar G, Gopala K. The Sphenoid Sinuses: Computed Tomographic Assessment of Septation, Relationship to the Internal
Carotid Arteries, and Sidewall Thickness in the Malaysian Population. J HK Coll Radiol 2001;4:185-8.

19. Çakur B, Sümbüllü MA, Yılmaz AB. A retrospective analysis of sphenoid sinus hypoplasia and agenesis using dental volumetric CT in Turkish individuals. Diagn Interv Radiol. 2011;17(3):205-8.

20. Bolger WE, Butzin CA, Parsons DS. Paranasal sinusBony anatomic variation and mucosal abnormalities: CT analysis for endoscopic sinus surgery Laryngoscope 1991;101:56-65.

\section{Source of Support: Nil; Conflict of Interest: None}

Submitted: 02-06-2019; Accepted: 10-08-2019; Published online: 04-09-2019 